\title{
Study on the Management Innovation in Enterprise Informatization Construction
}

\author{
Fang Yuan \\ Qingdao Huanghai University, Shandong, Qingdao, 266427, China
}

\begin{abstract}
With the advent of the information age, the rapid development of communication technology, information management model has gradually become one of the main ways of enterprise management, which marks the human society is towards a new era. Facing the fierce and brutal competition in the market, in order to create a broader space for their own development, enterprises must implement innovative management model to build information technology enterprise operating mechanism. Innovation management is the foundation of enterprise informationization. Enterprise informationization is an important measure to improve the management level. It is an effective way to realize breakthrough and innovative management. This paper makes a systematic exposition of enterprise information construction and innovation management.
\end{abstract}

Keywords: management innovation, enterprise, informatization construction

\section{Introduction}

The rapid development of science and technology, and promote the development of computer software technology. However, many enterprises in the process of specific implementation of the emergence of some problems, these problems are mainly reflected in: First, the enterprise information construction, business management innovation is not thorough enough understanding of the concept of enterprise information understanding biased. The subjective expansion of the mechanism, strategy, structure, organization and other areas of management innovation and related processes and activities too much emphasis. Second, the construction of information technology hardware network too much emphasis on 
business process reengineering, restructuring and other aspects of the management innovation is not enough attention to the enterprise's information network construction as a hard factor to carry out, although there are organizational innovation management performance contribution, but because of its non-dominant characteristics are difficult to quantify, and thus be over-ignored. For large and medium-sized enterprises in China, because they are faced with a strong international market competition, the market is facing an immature economic environment, companies only get rapid growth, is conducive to their own information, therefore, the enterprise information construction and business management innovation to fully integrate in order to enable enterprises to enhance their competitiveness.

\section{The meaning and role of enterprise information}

The so-called enterprise information, refers to the enterprise in every aspect of management, the use of modern information technology, enabling enterprises to speed up the transmission of information, speed up the processing and processing speed, and further the enterprise information resources are preserved, and To be fully utilized, and further for the enterprise management, staff to provide a reliable basis to promote the rapid improvement of enterprise management level. The enterprises to implement information technology, its role mainly in the following points: (1) to promote the improvement of enterprise management efficiency. Through the use of computer data processing, so that enterprises can provide timely management information. In the internal management of enterprises to establish the relevant network, not only can work between the various departments of enterprises have a rapid convergence, while the business processing speed can be improved, so that capital turnover speed, for enterprises to create a good economic benefits to lay a solid basis. (2) to reduce the intensity of the work of managers. Enterprise information, as long as the computer to enter the original record, which after the classification, calculation, storage and other related work, can be done by the computer automatically, further reducing the labour intensity of the staff. (3) to lay the foundation for the implementation of ecommerce. After the realization of enterprise information, further work for enterprises to carry out e-commerce prerequisites, and further promote the establishment of enterprise supply chain, so as to promote the whole society to speed up the flow of information. (4) to promote enterprise management practices. Enterprises in the construction of information, information-related data format, the source will have the corresponding regulatory requirements, compared to the previous manual operation, information technology to avoid the operation is more error-prone and non-standard problems, improve the work quality. 


\section{The relationship between enterprise information construction and management innovation}

Management innovation and enterprise information are closely related, the two are closely linked and indispensable.

Management innovation is the result of the development and application of information technology.

With the application of information technology, enterprise resource structure will change and the original corresponding management approach has gradually failed to meet the requirements of information technology, only through management innovation, to adapt to the new situation changes.

Management innovation is the core of enterprise information. Enterprise information is not a general sense of the use and innovation of new technologies, but a higher level of a new management revolution is the management approach and the concept of change, this deep-seated changes and enhance the development of technology alone is to achieve No, only the management level to keep up with the pace of information technology to ensure that the entire enterprise information construction of the final quality.

Management innovation is to achieve the basis of enterprise information. Enterprise information is an important measure to improve the management level, is to achieve effective management of innovative ways and important content, so they are you I, I have you, are complementary and mutually reinforcing relationship. It can be said in the enterprise information construction to strengthen management innovation is the core significance of the efficiency and effectiveness of the perfect unity. Information construction is mainly to improve the efficiency of business operations and management innovation is mainly to improve the effectiveness of business operations.

\section{The management innovation content in the enterprise information construction}

Enterprise information construction is accompanied by the entire process of change and innovation in management, for enterprises, how to implement the management philosophy and enterprise information construction and their own situation is far more than the introduction of a management concept is much more important. The introduction of new management ideas will inevitably bring change and impact to enterprises, enterprises must be combined with their own actual situation to know what they need, how to do, how to do, can not act rashly. For enterprises, in order to information construction and management innovation organically combine to find a reasonable "cut entrance" is essential. 


\subsection{The management mode innovation in the information management}

Enterprise management model refers to the management activities of the internal mechanisms and management elements of the relationship between the descriptions. There is no doubt that we are or have been moving from large industrial era to the era of knowledge economy, in this process, the management model inevitably a change. Fundamentally speaking, it should change from strict hierarchical system to humanistic network. From different perspectives, the innovation of management mode mainly includes the following several links.

In traditional enterprises, the model of management control is realized from the top to the bottom of the command chain. Today, with the globalization of the market and the constant concentration of geopolitics, this form of implementation has been difficult, and network is a continuous contact with others in the process, people can not be bound by the command chain and direct contact to information resources. Information technology provides an ideal communication and contact platform for personnel at all levels and departments of the enterprise, which makes various management instruction, feedback information and other resources convenient and quick to reach the target object accurately through geographical and space constraints.

Strict hierarchical enterprises with command and control structure, instructions from the top, grass-roots personnel are difficult to play a subjective initiative and creativity. While modern enterprises require coordination between the relevant work and middle-level personnel, this coordination of the performance of enterprises to become a powerful team. In the traditional management model, the enterprise managers in the centre of the entire team, played the role of commander, the rest of the members of the work should be carried out around his instructions, so that the ability of the entire team did not get the best Play. If the former role because the manager is limited by the conditions only by the order to ensure the realization of management intentions, that with the continuous improvement of the level of information, a variety of advanced technology and means to greatly enhance the management of the scope of management, To expand their horizons and improve their ability, this time managers can be more personally involved in specific business practice, playing a role of a participant, so that it can better mobilize the enthusiasm of all members of the work, To play the whole team's collective advantage. In the advanced stage of enterprise information development, managers have been able to pull out from a specific business, at a higher level to consider the strategic development and decisionmaking issues, this time the manager is a coordinator role.

\subsection{The management organizational innovation in the informationization}

The organization and management mode adapting to the industrial economy, social production status and technical base is the pyramid form, the top-down hierarchical control organization form under the traditional organization theory, namely the hierarchical organizational structure. The role of middle management is integrated from the top of the information, guidance, supervision and control of 
subordinates. In order to ensure responsibility and the task is completed, each person has only one boss, subordinates obey the superior. This organizational structure is characterized by emphasis on professional division of labour, economic scale, orderly transmission, hierarchical. However, in the information age, this organizational structure exposed more and more problems.

\subsection{The management technological innovation in the information construction}

Management technology refers to the specific conditions to solve specific management problems in the procedures and methods, is the management principle in specific conditions. Management technology innovation is the basic innovation activity which runs through the whole management activity. It is the process of "gaining management advantage in market, recombining management resources and realizing organizational innovation benefit with more effective management behaviour".

\section{Conclusion}

In the information construction process, the first principle of enterprise management technology innovation is to combine their situation and be targeted. Because the environmental factors and internal factor endowments of enterprises in different countries and regions are different, the introduction, application and innovation of advanced management techniques should be continuously reformed according to their own situation, make the management principles, the enterprise environment and elements organically combined.

\section{References}

[1] Chen Nian, Lei Ling. Enterprise Informatization and Enterprise Management Innovation. Contemporary Manager, 55(12), pp.68-70, 2011

[2] Lu Wenyi. Innovation of Enterprise Management in Information Age Information and Communications, 8 (5), pp.87- 91, 2013

[3] Zhang Yongsheng. Enterprise Informatization Construction and Business Management Innovation, 12(10), pp. 18- 20, 2012

[4] Shiquan Quan. Research on the Innovation of Enterprise Management in the Information Society, Economy and Management, 9(6), pp.58- 61, 2011

[5] Wei Yin Yin. What informationization means to the social economy? Business research, 8(4), pp.85-87, 2014 